\title{
MARXISMO E EDUCAÇÃO: CONTRIBUIÇÃO AO DEBATE SOBRE A TEORIA EDUCACIONAL E A TRANSIÇÃO
}

\author{
Celi Nelza Zülke Taffarel ${ }^{1}$
}

\section{RESUMO:}

O texto apresenta argumentos, considerando contribuições de base marxista, sobre um dos desafios da atualidade na educação, relacionado a construção da teoria educacional e pedagógica, na transição do modo de produção capitalista ao modo de produção comunista. Palavras-chave: Teoria Educacional; Marxismo e Educação; Teoria da Transição.

\section{MARXISM AND EDUCATION: CONTRIBUTION TO THE DEBATE ON TRANSITION AND EDUCATIONAL THEORY}

\begin{abstract}
:
The text presents arguments, considering the basic Marxist contributions on one of today's challenges in education, related to construction of educational theory and pedagogy, the transition from the capitalist mode of production to the communist mode of production. Keywords: Educational Theory, Marxism and Education, Theory of Transition.
\end{abstract}

\section{INTRODUÇÃO}

Um espectro ronda a educação do Brasil. Esse espectro é o marxismo. Quem não vem recebendo ataques, da direita e da esquerda, por ser considerado marxista? Quem ainda não ouviu críticas e acusações por defender o marxismo? Quem ainda não sofreu represálias por ser reconhecido marxista? Duas conclusões decorrem daí. O marxismo é reconhecido como força teórica que influencia a educação e seus rumos. É tempo dos marxistas exporem, à face do mundo inteiro, seu modo de ver, seus pontos de vista e suas tendências frente à transição do capitalismo ao comunismo ${ }^{2}$.

Aludindo aos primeiros parágrafos do Manifesto do Partido Comunista (MARX; ENGELS, 1998), expomos de forma sintética uma posição em relação ao tema Marxismo $e$ Educação. Estamos partindo de duas referências, entre muitas outras existentes, a respeito do tema reconhecendo a necessidade do avanço teórico, e dentro dele, de uma teoria da transição, alicerçada na referência marxista para a educação.

O capitalismo está demonstrando sua exaustão, decomposição e degeneração, com severas consequências para a classe trabalhadora. A vida na terra poderá se tornar inviável. Essa degeneração e decomposição já foi detectada científica e politicamente, desde o Manifesto do Partido Comunista (escrito por Marx e Engels, em 1848), às Teses de Abril (escritas por Lênin, em 1917) e ao Programa de Transição (escrito por Trotsky, em 1938). Urge, portanto, avançarmos na consolidação da referência teórica marxista para subsidiar a teoria educacional e pedagógica.

As teorias educacionais hegemônicas estão sendo severamente criticadas em decorrência de seus limites explicativos e capacidade de desmobilização política. Essa crítica vai desde as teorias sobre a sociedade do conhecimento, ao construtivismo, às teorias do cotidiano, (DUARTE 2001; 2003; 2004a, 2004b; 2004c), a produção do conhecimento e a política de formação docente (MARCONDES DE MORAES, 2003); críticas ao professor reflexivo-pesquisador (VIANA, 2011), passando pela crítica à 
pedagogia do capital (NEVES, 2005), ao projeto de mundialização da educação (MELO, 2004) e, recentemente, a crítica realizada por Frigotto (2010) à política educacional do governo de Luiz Inácio Lula da Silva, apresentada na Reunião Anual da Associação Nacional de Pós-Graduação e Pesquisa em Educação (ANPED). Segundo Frigotto,

\begin{abstract}
A junção da fragmentação ao abandono do campo crítico na disputa pelo projeto educativo e o foco de atendimento da grande massa desorganizada e despolitizada resultou naquilo que foi dominante na educação durante a década - a política da melhoria mediante as parcerias do público e privado. Desse desfecho resulta que no plano estrutural reiteram-se as reformas que mudam aspectos do panorama educacional sem alterar nossa herança histórica que atribui caráter secundário à educação como direito universal e com igual qualidade. Não só algo secundário, mas desnecessário para o projeto modernizador e de capitalismo dependente aqui viabilizado. No plano das políticas educacionais, da educação básica à pós-graduação, resulta, paradoxalmente, que as concepções e práticas educacionais vigentes na década de 1990 definem dominantemente a primeira década do século $\mathrm{XXI}$, afirmando as parcerias do público e privado, ampliando a dualidade estrutural da educação e penetrando, de forma ampla, mormente nas instituições educativas públicas, mas não só, e na educação básica, abrangendo não só o conteúdo do conhecimento como também os métodos de sua produção ou socialização. A não-mudança estrutural a que me refiro pode ser nitidamente percebida pela leitura de balanços síntese feitos por três intelectuais ${ }^{3}$ representantes do pensamento crítico, os quais evidenciam que, tomados os últimos 80 anos, a prioridade da educação sustenta-se apenas no discurso retórico (FRIGOTTO, 2010, P. 9-10)
\end{abstract}

Urge uma teoria da transição de base marxista que fundamente a práxis educacional. Para contribuir com o debate, buscando avanços teóricos, vamos nos valer de dois textos que tratam do tema Marxismo e Educação.

A primeira referência é o texto apresentado pelo professor Dermeval Saviani em sua conferência durante o III Encontro Brasileiro de Educação e Marxismo (EBEM), ocorrido em Salvador/BA, no ano de $2007^{4}$. Destacamos o EBEM porque é a mais explícita evidência do vigor da teoria marxista fundamentando a teoria educacional. Portanto, é dentro desta tradição ${ }^{5}$ que elegemos um texto (SAVIANI, 2007c) para fomentar o presente diálogo.

A segunda referência que vamos considerar no presente diálogo é o livro organizado por José Claudinei Lombardi e Dermeval Saviani (2005), resultante dos colóquios de Filosofia e História da Educação promovidos pelo Grupo de Estudos e Pesquisas História, Sociedade e Educação no Brasil (HISTEDBR) e o Grupo de Estudos e Pesquisas em Filosofia da Educação (PAIDEIA), ambos do Departamento de Filosofia e História da Educação da Faculdade de Educação da Universidade Estadual de Campinas (UNICAMP). O livro apresenta também as mesas redondas do II Colóquio Marx e Engels, promovido pelo Centro de Estudos Marxistas (CEMARX), do Instituto de Filosofia, Ciências Sociais e História da UNICAMP e pela Universidade Federal de Uberlândia (UFU).

Destacamos esses dois eventos por demonstrarem, pelo número de eventos realizados e número de trabalhos inscritos, bem como, pela densidade teórica, que a temática Marxismo e Educação está, cada vez mais, adquirindo vigor e fôlego, o que é 
alvissareiro e demonstra um reconhecimento do marxismo, em tempos de decomposição e degeneração capitalista, tempos históricos de imposturas intelectuais, tempos de retrocesso da teoria, tempos de desafios frente à necessidade da transição para o comunismo.

Destacamos do III EBEM o texto de Saviani por tratar da temática Marxismo $e$ Pedagogia, a partir do que queremos dialogar sobre os fundamentos de uma pedagogia de base marxista. Destacamos o livro de Lombardi e Saviani, com quem também queremos dialogar sobre a complexidade do pensamento marxista e seus desdobramentos para o campo educacional em tempos de transição.

A hipótese que levantamos nesse diálogo é de que o marxismo - por trazer em si uma dada filosofia, cuja raiz é o ser humano e sua emancipação, ou seja, a filosofia da práxis; a explicação sobre o conhecimento e a crítica radical às relações sociais dos modos de produção econômica, ou seja, a lógica e teoria do conhecimento materialista histórica dialética e; o projeto histórico comunista como teleologia - é o alicerce teórico consistente para fundamentar a teoria educacional e pedagógica na transição para a superação do modo do capital organizar a produção dos bens materiais e imateriais.

\section{DESENVOLVIMENTO}

Inicialmente apresentaremos os argumentos de Saviani (2007c) para demonstrar sob que base teórica, sob que princípios, a partir da obra de Marx, está alicerçada a educação de base marxista e qual é a sua contribuição para construir no Brasil a pedagogia histórico-crítica. Em seguida, apresentaremos os pontos centrais dos textos incluídos no livro de Lombardi e Saviani (2007), sobre Marxismo e Educação, para, então, concluirmos sobre as bases marxistas de uma teoria educacional e pedagógica em um tempo histórico de transição.

\subsection{As primeiras aproximações de Saviani a uma teoria educacional de base marxista}

Saviani nos demonstra que Marx, fundador da filosofia da práxis, não se ocupou direta e especificamente da elaboração teórica no campo da educação, mas que é possível, no conjunto de sua obra, identificar as passagens referidas à educação, e ainda, que é possível extrair das análises sobre a história, a economia e a sociedade derivações de sentido para a educação. Isso é constatável, segundo o autor, nas obras de Dommanget: $O s$ grandes socialistas e a educação: de Platão a Lênin (1972); de Rossi: Pedagogia do trabalho: raízes da educação socialista (1981); de Dangeville: Marx e Engels: crítica da educação e do ensino (1976); de Manacorda: Marx e a pedagogia moderna (1991); e de Suchodolski: Teoria marxista da educação (1966), entre outras.

Coube a Manacorda, segundo Saviani $(2007 \mathrm{c})$, o mérito de realizar o primeiro rastreamento de todos os textos na sua integralidade, o que resultou no livro Il marxismo $e$ l'educazione, publicado em 1964. Depois, ainda destacou os aspectos mais significativos daquela discussão, no livro Marx e a pedagogia moderna. Saviani destaca que Manacorda realizou um cuidadoso estudo filológico visando, como ele mesmo diz, "devolver a Marx o que é de Marx, a Lênin o que é de Lênin e aos outros o que é deles" (MANACORDA, 1991, p.102).

Ainda segundo Saviani, Manacorda distingue três momentos da obra de Marx que se relacionam à Educação:

a) 1847-1848 - quando sobressai o texto do Manifesto do Partido Comunista, de 1848, correlacionado ao texto Princípios do Comunismo, redigido por Engels em 1847, destacando-se a passagem sobre o ensino público e gratuito para todas as crianças, a abolição do trabalho infantil nas fábricas e a unificação do ensino com a produção material. 
b) 1866-1867 - momento em que foi redigido o texto Instruções aos delegados do Conselho Geral Provisório do I Congresso da Associação Internacional dos Trabalhadores, articulado às passagens de $O$ Capital referidas à educação. Marx se manifesta, no texto das Instruções, sobre o conteúdo pedagógico que, a seu ver, deve constituir o ensino de caráter socialista, destacando três elementos: o ensino intelectual, a educação física e a educação tecnológica (transmissão dos fundamentos científicos gerais de todos os processos de produção e introdução ao uso prático e capacidade de manejo dos instrumentos elementares de todos os ofícios).

Seu êxito demonstrou pela primeira vez a possibilidade de vincular o ensino e a ginástica com o trabalho manual e daí também o trabalho manual com o ensino e a ginástica (MARX, apud SAVIANI, 2007c, p.3).

Marx indica a potencialidade do "ensino do futuro" que se manifesta sobre a base da grande indústria e um dos elementos desse processo de subversão,

desenvolvido espontaneamente sobre a base da grande indústria, são as escolas politécnicas e de agronomia, um outro elemento são as "écoles d'enseignement professionel', nas quais os filhos dos operários recebem algum ensino de tecnologia e do manejo prático dos diferentes instrumentos de produção. Se a legislação sobre as fábricas, que é a primeira concessão arrancada, com muito esforço, do capital, combina com o trabalho de fábrica apenas o ensino elementar, não há dúvida de que a inevitável conquista do poder político por parte da classe operária conquistará também lugar nas escolas dos operários para o ensino tecnológico teórico e prático (MARX, apud SAVIANI, 2007c, p.3).

c) 1875 - ano da redação das Notas à margem do Programa do Partido Operário Alemão, conhecidas como Crítica ao Programa de Gotha. É a intervenção de Marx no programa de unificação dos dois partidos operários alemães quando observa, sobre a educação:

Educação popular (ou ensino elementar) para todos? O que se quer dizer com essas palavras? Acredita-se, talvez, que na sociedade atual (e apenas dessa se trata) o ensino possa ser igual para todas as classes? Ou, então, pretende-se que as classes superiores devam ficar coativamente limitadas àquele pouco de ensino - a escola popular - única compatível com as condições econômicas, tanto dos trabalhadores assalariados quanto dos camponeses?... Ensino geral obrigatório, instrução gratuita... O parágrafo sobre as escolas deveria, pelo menos, pretender escolas técnicas (teóricas e práticas) em união com a escola popular... Proibição (geral) do trabalho das crianças... Sua efetivação - se fosse possível - seria reacionária porque, ao regulamentar severamente a duração do trabalho segundo as várias idades e ao tomar outras medidas preventivas para a proteção das crianças, o vínculo precoce entre o trabalho produtivo e o ensino é um dos mais potentes meios de transformação da sociedade atual (MARX, apud SAVIANI, 2007c, p.4).

Além dessas principais menções de Marx ligadas à educação e ao ensino, Saviani destaca, quanto às derivações de sentido para a educação, obtidas a partir da consideração do conjunto da obra de Marx e Engels, o esforço de Suchodolski, que publicou, em 1961, o livro Teoria marxista da educação. Segundo Saviani: 
O ponto de partida dessa obra é uma análise da evolução dos problemas pedagógicos nos escritos de Marx e Engels (Cap. I) em que considera a trajetória de seus escritos, desde os primeiros textos até "O Capital". O segundo capítulo é dedicado a mostrar o diagnóstico da atualidade de Marx e Engels em que se analisa o desenvolvimento histórico do capitalismo com as implicações para os indivíduos e as classes, em particular para o proletariado, o problema do tempo livre, a derrocada da ordem classista e a libertação do homem. O terceiro capítulo trata dos problemas da alienação e do fetichismo para concluir com o significado pedagógico da alienação. No terceiro capítulo, denominado "O significado da revolução socialista para a educação", é abordado o caráter de classe do sistema de ensino na sociedade burguesa, o ensino dos filhos de operários, o vínculo ensino-trabalho como gérmen da educação socialista, a organização das massas e a luta pela concepção materialista revolucionária da educação. O capítulo se encerra com considerações sobre a questão da educação moral, cujo centro é a participação dos homens na luta pelo progresso social. Com isso, a visão socialista da educação moral se opõe "tanto aos sistemas burgueses do hedonismo e utilitarismo como também aos sistemas do rigorismo ético e do formalismo" (p. 160). Os capítulos seguintes tratam dos fundamentos da teoria marxista da cultura (Cap. V), da crítica da concepção metafísicoidealista do homem (Cap. VI), dos acertos e erros do materialismo metafísico na análise do homem (Cap. VII) e da luta pela teoria materialista da personalidade (Cap. VIII). Finalmente, o capítulo IX, tem caráter de síntese conclusiva versando sobre "o significado de Marx e Engels para a história da pedagogia" (SAVIANI, 2007c, p.4).

Saviani defende que a concepção elaborada por Marx partiu do ponto mais avançado atingido pela modernidade expresso pela filosofia de Hegel, efetuou sua crítica e inverteu os termos do problema posto pelo pensamento moderno desautorizando o idealismo. Portanto, então, não se trata de uma concepção inserida nos limites do pensamento moderno. Transcende a ele.

Não é, pois, uma concepção ultrapassada, mas se insere plenamente no debate contemporâneo [ . . . ] O empenho em compreender e explicar a problemática educativa a partir dessa concepção superadora do pensamento burguês moderno, eis o que se configura como uma teoria marxista da educação. Tal teoria claramente realista, em termos ontológicos, e objetivista, em termos gnosiológicos, move-se no âmbito de dois princípios fundamentais: 1 . As coisas existem independentemente do pensamento, com o corolário: é a realidade que determina as idéias e não o contrário; 2. A realidade é cognoscível, com o corolário: o ato de conhecer é criativo não enquanto produção do próprio objeto de conhecimento, mas enquanto produção das categorias que permitam a reprodução, em pensamento, do objeto que se busca conhecer (SAVIANI, 2007c, p.6-7).

Em sua exposição, Saviani (2007c) conclui que para a construção de uma pedagogia inspirada no materialismo histórico

não basta recolher as passagens das obras de Marx e Engels diretamente referidas à educação, como o fizeram Dommanget (1972, p. 321-348), 
Rossi (1981; 1982), Dangeville (1976) e mesmo Manacorda (1964; 1991), que acrescenta lúcidas e pertinentes reflexões úteis, sem dúvida, à construção de uma pedagogia marxista. Também não é suficiente perscrutar as implicações educacionais do conjunto da obra dos fundadores do materialismo histórico, como o fez Suchodolski (1966).Penso que a tarefa da construção de uma pedagogia inspirada no marxismo implica a apreensão da concepção de fundo (de ordem ontológica, epistemológica e metodológica) que caracteriza o materialismo histórico. Imbuído dessa concepção, trata-se de penetrar no interior dos processos pedagógicos, reconstruindo suas características objetivas e formulando as diretrizes pedagógicas que possibilitarão a reorganização do trabalho educativo sob os aspectos das finalidades e objetivos da educação, das instituições formadoras, dos agentes educativos, dos conteúdos curriculares e dos procedimentos pedagógicodidáticos que movimentarão um novo éthos educativo voltado à construção de uma nova sociedade, uma nova cultura, um novo homem, enfim (SAVIANI, 2007c, p.10).

Nesse sentido, o autor apresenta as primeiras aproximação a formulação da proposta da pedagogia histórico-crítica, recorrendo a alguns textos fundantes de Marx, especificamente à distinção entre produção material e não-material, tendo em vista a caracterização na natureza e especificidade da educação (MARX, 1978).

Para estruturar o método da pedagogia histórico-crítica, recorreu ao texto $O$ método da economia política (MARX, 1973, p.228-240), a partir do que indica de onde retirava o critério de cientificidade do método pedagógico proposto e nos diz:

não é do esquema indutivo tal como o formulara Bacon; nem é do modelo experimentalista ao qual se filiava Dewey. É, sim, da concepção dialética de ciência tal como a explicitou Marx no 'método da economia política', concluindo que "o movimento que vai da síncrese ('a visão caótica do todo') à síntese ('uma rica totalidade de determinações e relações numerosas') pela mediação da análise ('as abstrações e determinações mais simples') constitui uma orientação segura tanto para o processo de descoberta de novos conhecimentos (o método científico) como para o processo de transmissão-assimilação de conhecimentos (o método de ensino) (SAVIANI, 2007c, p.10-11).

Saviani utiliza-se, em sua aproximação, da obra de Gramsci considerando que, dentre os teóricos marxistas, foi o que mais avançou na discussão da questão escolar, lançando mão da categoria "catarse" para caracterizar o quarto passo do método da pedagogia histórico-crítica, constitituvo do momento culminante do processo educativo, quando o educando ascende à expressão elaborada da nova forma de entendimento da prática social, entendendo-se "catarse", como

a "elaboração superior da estrutura em superestrutura na consciência dos homens" (GRAMSCI, 1978, p. 53) [que] se revelava perfeitamente adequada para exprimir o momento da efetiva incorporação dos instrumentos culturais, transformados, pela mediação do trabalho pedagógico, em elementos ativos de transformação social (SAVIANI, 2007c, p.11). 
Foi ainda em Gramsci que Saviani se inspirou para indicar o caminho para a construção de um currículo escolar adequado às condições atuais próprias desse período de transição da forma social capitalista para uma sociedade socialista:

o eixo da organização da educação escolar nas condições da nossa época me foi suscitado pela problematização efetuada por Gramsci $(1975$, vol. III, p. 1544-1546; na edição brasileira, 1968, p. 134-136) em sua reflexão sobre a questão escolar. Reporto-me à passagem em que ele se referia à centralidade que tinha a cultura greco-romana na velha escola, traduzida no cultivo das línguas latina e grega e das respectivas literaturas e histórias políticas. Constituía-se, por esse caminho, o princípio educativo da escola tradicional, "na medida em que o ideal humanista, que se personifica em Atenas e Roma, era difundido em toda a sociedade", sendo "um elemento essencial da vida e da cultura nacionais" (SAVIANI, 2007c, p.11).

Saviani, em sua aproximação a uma pedagogia de base marxista, ressalta que a História é a matéria que ocuparia o lugar central no novo princípio educativo da escola do nosso tempo:

uma escola unitária porque guiada pelo mesmo princípio, o da radical historicidade do homem e organizada em torno do mesmo conteúdo, a própria história dos homens, identificado como o caminho comum para formar indivíduos plenamente desenvolvidos. Com efeito, que outra forma poderíamos encontrar de "produzir, em cada indivíduo singular, a humanidade que é produzida histórica e coletivamente pelo conjunto dos homens" (SAVIANI, 2005, p. 13), senão fazendo-os mergulhar na própria história e, aplicando o critério do "clássico", permitir-lhes vivenciar os momentos mais significativos dessa verdadeira aventura temporal humana? (SAVIANI, 2007c, p.12).

Estas são indicações de aproximações de uma pedagogia inspirada e construída em consonância com os princípios teórico-práticos do materialismo histórico. Essa construção não é uma tarefa individual. Esse processo de construção, segundo Saviani, necessita ter prosseguimento ${ }^{6}$.

Saviani iniciou suas discussões sobre a pedagogia histórico-crítica em 1979 com a primeira turma de doutorado da PUC-SP. Dessas primeiras aproximações decorreram trinta anos comemorados no período de 15 a 17 de novembro de 2009, em evento realizado na Universidade Estadual Paulista "Júlio de Mesquita Filho" (UNESP), de Araraquara. O evento foi organizado pelo Grupo de Pesquisa "Estudos Marxistas em Educação", com o objetivo de aprimorar as reflexões sobre a pedagogia histórico-crítica e seus avanços, bem como divulgar os trabalhos produzidos por este grupo de pesquisa na perspectiva teórica marxista.

Hoje são perceptíveis os sinais de revigoramento do interesse pela abordagem marxista nos vários campos da prática social, inclusive a educação. As obras de Dermeval Saviani e a produção científica disseminada por outros acadêmicos marxistas alinhados à proposta da pedagogia histórico-crítica são exemplos da vitalidade dessa corrente pedagógica.

Sem desconsiderar as críticas formuladas à pedagogia histórico-critica, expressa, por exemplo, nos textos de Freitas (1995) em relação à concepção do papel social da escola, da organização do trabalho pedagógico e do trato com o conhecimento, ou a formulação recentemente produzida por Ademir Quintilio Lazarini (2010), que critica as 
teses matriciais de Saviani, quando se reporta à obra de Marx de maneira problemática e/ou equivocada quanto às principais categorias econômicas a respeito da relação entre capital e educação escolar, ela é uma construção da teoria educacional e pedagógica de base marxista, das mais avançadas, no Brasil.

\subsection{O debate contemporâneo sobre marxismo e educação}

Tomando como referência os eventos científicos referidos anteriormente, organizados por grupos de pesquisa reconhecidos em nosso país, podemos constatar que o marxismo enquanto filosofia, teoria do conhecimento e projeto histórico perpassa as elaborações aí expostas. Valendo-nos das contribuições de Andreotti (2007) localizamos os pontos centrais dos textos aí presentes e concluímos com as ideias que seguem.

No primeiro texto, Educação, ensino e formação profissional em Marx e Engels, José Claudinei Lombardi aborda o contexto das propostas pedagógicas burguesas e socialista no século XIX e traz uma breve discussão sobre a educação, o ensino e a formação profissional na obra de Marx e Engels, assinalando ainda as contribuições de Lênin, Krupskaja e Makarenko na conformação de uma proposta pedagógica comunista.

No segundo texto, de José Carlos de Souza Araújo, $O$ embate marxiano com a construção dos sistemas educacionais, é debatida pontualmente a educação escolar na obra de Marx. Embora não tenha dedicado uma obra à educação, Marx, em inúmeras passagens, fez referência a esse campo de estudo. Araújo trata, a partir da obra marxiana, de questões relativas aos embates com a constituição dos sistemas educativos no contexto europeu e norte americano do século XIX.

O terceiro texto apresenta o tema Dialética e pesquisa em educação, de José Luís Sanfelice, que apresenta uma discussão sobre as diferenças entre a dialética no pensamento idealista de Hegel e no pensamento materialista de Marx. A respeito do campo da pesquisa em educação, Sanfelice destaca a supremacia do relativismo da verdade e do subjetivismo como uma tendência atual e a necessidade da retomada dos autores clássicos para alicerçar a pesquisa em ciências humanas. Ressalta que o relativo, na pesquisa, não é a impossibilidade do conhecimento e, sim, o reconhecimento da complexidade do fenômeno em sua totalidade e movimento.

O quarto texto é de autoria de Máuri de Carvalho, e trata do tema Lênin, educação e consciência socialista. Carvalho examina a obra de Lênin apresentando a educação como instrumento para a formação da consciência socialista. No decorrer do texto, o autor faz algumas considerações sobre o marxismo e seu método de análise em Lênin. Carvalho assinala o papel da escola na sociedade capitalista como espaço ambíguo de reprodução e transformação. Ressalta ainda a contribuição de Lênin na construção de uma pedagogia socialista, finalizando sobre a educação politécnica.

O quinto texto, com o título Conhecimento e disputa pela hegemonia: reflexões em torno do valor ético-político e pedagógico do senso comum e da filosofia em Gramsci, de autoria de Marcos Francisco Martins explicita as consequências das mudanças no modelo de produção na passagem para o século XX, que alteraram profundamente as relações de produção e de trabalho. $\mathrm{O}$ autor discorre sobre a obra de Gramsci no contexto da sociedade italiana da primeira metade do século XX, que ao ter como referência os princípios do marxismo, forjou uma teoria que consubstanciou a relação entre o conhecimento, a política e a educação.

$\mathrm{O}$ sexto texto traz A contribuição do pensamento de Althusser para a análise da função social da educação. O tema é tratado por Marcos Cassin. O autor aborda os limites e a contribuição da Nova Sociologia da Educação ou Sociologia do Currículo, que desloca a análise sociológica para o interior da escola. Sobre a importância de a Sociologia retomar 
a temática da educação e sua relação com os aspectos sociais mais amplos, Cassin assinala a necessidade da recuperação dos teóricos da Sociologia da Educação Crítica e do referencial de Althusser na sua análise sobre a concepção de Estado e de ideologia e na definição de Aparelho Ideológico de Estado.

O sétimo texto é de autoria de Carlos Lucena e intitula-se Marxismo, crise do capitalismo monopolista e qualificação dos trabalhadores. Trata da construção das crises do capitalismo na análise de Marx, que parte da produção capitalista e do processo de desequilíbrio entre esta e o consumo. Lucena apresenta, ainda, autores de várias gerações que dialogam com a obra marxiana nessa análise. O autor aborda a crise atual do capitalismo e o aspecto contraditório da formação dos trabalhadores nesse contexto, tais como seletividade e desemprego; o discurso ideológico da seletividade como fator de homogeneidade, como também que a inserção da ciência, por meio da maior escolaridade exigida do trabalhador, aumenta a composição do capital em detrimento do trabalho.

$\mathrm{O}$ oitavo texto intitula-se Por que é necessário uma análise crítica marxista do construtivismo, de autoria de Newton Duarte, em que ressalta que é indispensável esclarecer as divergências e as diferenças entre a pedagogia marxista e outras teorias pedagógicas. Sobre a possibilidade da construção de uma pedagogia marxista na sociedade capitalista, o autor, afirmando os limites de tal empreitada, assinala que essa construção deve compor o processo de superação da sociedade capitalista. Duarte aponta, nessa trajetória, a necessidade da crítica ao construtivismo e às pedagogias que fazem parte do pensamento burguês contemporâneo.

O nono texto, de autoria de Dermeval Saviani, Educação socialista, pedagogia histórico-crítica e os desafios da sociedade de classes parte da concepção marxista de homem, para abordar as concepções de educação burguesa e socialista. O autor formula uma questão: na sociedade capitalista é possível articular a escola com os interesses dos trabalhadores? Ao apontar a diferença entre as teorias educacionais e as pedagógicas, Saviani discorre sobre as tendências pedagógicas tradicional e renovadora e o desafio permanente entre a ênfase nas teorias do ensino e nas teorias da aprendizagem. Assinala ainda a pedagogia histórico-crítica como a que aborda, em termos dialéticos, teoria e prática e finaliza com os desafios pedagógicos no contexto brasileiro, tais como a ausência de um sistema de ensino e a descontinuidade dos programas governamentais.

Podemos concluir pelo destacado na obra que o tema Marxismo e Educação vem sendo tratado no Brasil tanto a partir da obra de Marx, Engels, Lênin, Gramsci, quanto de obras dos interlocutores dos clássicos - Althusser, Saviani, entre outros. Esses textos traduzem a contribuição do pensamento marxiano para a história e para o entendimento dos mecanismos do sistema capitalista de produção e a formação humana, a educação escolarizada.

A ausência sentida nos textos apresentados, advém da luta pela terra, a luta pela reforma agrária, a luta dos movimentos sociais. Fica uma lacuna a ser preenchida em próximos eventos. Isso porque, provavelmente, é desse âmbito da luta de classes, contra a propriedade privada da terra, que estão sendo formuladas teorias educacionais de base marxista que permitem reconhecer avanços teóricos na Educação do Brasil que criticam a escola capitalista.

Portanto, três são as características do livro Marxismo e Educação organizado por Lombardi e Saviani. Uma diz respeito a ausência do debate teórico com os que enfrentam, a partir da luta pela terra, a elaboração da teoria pedagógica. Outras duas dizem respeitos aos textos presentes no livro. É que alguns artigos referem-se diretamente ao pensamento de Marx e Engels, enquanto outros se voltam para pensadores que tiveram como fonte a obra marxiana. A outra diz respeito ao que provavelmente moveu a sua publicação: a 
atualidade do marxismo na crise do pensamento contemporâneo; contemporaneidade que apregoa o fim das ideologias e o fim da história. Crise que vem sendo enfrentada, mesmo que de maneira tênue, pelos que buscam na referência marxista, o aporte teórico para desenvolver uma teoria da transição que responda aos desafios do tempo histórico (MÉSZÁROS, 2007). Crise que exige a materialização do apelo que Marx e Engels colocam no final do Manifesto do Partido Comunista - "Trabalhadores do mundo univos".

\section{CONCLUINDO}

Podemos concluir, a partir da análise do texto de Saviani, datado de 2007, exposto no III EBEM, que, apesar das críticas formuladas à pedagogia histórico-crítica (FREITAS, 1995; LAZARINI, 2010), como já referido, ela é uma construção da teoria educacional e pedagógica de base marxista das mais avançadas no Brasil. É nessa formulação que vamos localizar uma das proposições mais avançadas da pedagogia de base marxista no Brasil. Não é a única proposição de base marxista no campo da Educação, pois podemos mencionar outros exemplos, que não serão aqui analisados, tais como a Pedagogia do Movimento dos Trabalhadores Rurais Sem Terra (CALDART, 2004; MST 2005; VENDRAMINI, 2009; D`AGOSTINI, 2009), a Metodologia de Ensino Crítico-Superadora (COLETIVO DE AUTORES, 1992) - que propõem uma dada concepção de organização curricular, a partir da crítica à escola capitalista, da posição de classe em defesa dos interesses da classe trabalhadora e da teleologia que coloca a transição para o comunismo como desafio a humanidade. Proposições estas que reconhecem que a educação da classe trabalhadora transcende a escola e, portanto, tem que ser assim considerada, no âmbito da política cultural, econômica e política. Esses exemplos permitem reconhecer a necessidade de aprofundamento do tema.

O que vamos localizar de comum e unificador nas proposições é a aproximação à teoria marxista, ou seja, a uma dada filosofia - filosofia da práxis - a uma dada teoria do conhecimento - o materialismo histórico dialético - e a um dado projeto histórico para além do capitalismo. No entanto, divergem nas táticas e nas premissas programáticas. Isto é evidente quando nos perguntamos sobre as proposições superadoras, quando nos perguntamos pelas reivindicações transitórias.

Podemos concluir, ainda, que, conforme apontado nas diversas edições do EBEM, pensar as possibilidades de uma educação na perspectiva da emancipação humana ${ }^{7}$ exige a compreensão de sua finalidade última que, por sua vez, necessita da compreensão ontológica do ser humano. A ontologia é, juntamente com a história, o aporte que permite explicar o ser humano, suas formações econômicas e o conhecimento. Esta compreensão vem sendo negada no interior dos cursos de formação de professores no Brasil, basta analisarmos os currículos para constatar tal fato.

Os textos aqui analisados, nos eventos delimitados, por mais que apresentem divergências internas e partam de diferentes contribuições da obra marxista, permitem reafirmar o marxismo como fundamental para construir alternativas conjunturais que potencializem a ação das classes trabalhadoras no enfrentamento cotidiano das práticas que buscam negar as possibilidades de superação radical do capitalismo, ou seja, da atual sociabilidade. A ontologia marxiana nos permite compreender a realidade não apenas para a sua manipulação, mas como práxis de intervenção na direção da nova sociabilidade. Permite-nos reconhecer a estratégia e as táticas para enfrentar a luta de classes e, dentro dela, a defesa da educação pública, de qualidade, socialmente útil. Reconhecer que não podemos separar as premissas teóricas das programáticas. E isso significa que temos que avançar na educação brasileira em um programa de transição que permita a unidade na luta 
contra o inimigo comum, a classe burguesa, a família burguesa e os valores burgueses, o Estado capitalista e a propriedade privada dos meios de produção. Temos exemplos históricos desta luta. 2011 é o ano de comemorarmos os 140 anos da Comuna de Paris, evento histórico em que foram levantadas as principais bandeiras a respeito da educação pública, laica, para todos na humanidade. O Conselho Geral da Associação Internacional dos Trabalhadores (AIT) destacava em seu comunicado

A Comuna prova que, em contraste com a velha sociedade, com as suas desgraças econômicas e o seu delírio político, vai nascendo uma sociedade nova cujo governo internacional será a Paz, porque o seu governante nacional será por toda a parte o mesmo - o Trabalho! (Primeira mensagem do Conselho Geral da Associação Internacional dos trabalhadores sobre a Guerra Franco-Prussiana).

A hipótese que levantamos neste diálogo, no inicio do texto é confirmada pelo teor dos textos apresentados na análise. O marxismo, por trazer em si uma dada filosofia, cuja raiz é o ser humano e sua emancipação, a explicação sobre o conhecimento e a crítica radical às relações sociais dos modos de produção econômica é a base teórica necessária, porque vital, para o tempo histórico e seus desafios e, portanto, para fundamentar a formação de professores. O marxismo traz em si a filosofia da práxis, a lógica e a teoria do conhecimento materialista histórica dialética e o projeto histórico comunista, que implicam, além da formulação de premissas teóricas, premissas programáticas, ou seja, um programa de transição. É, portanto, como demonstram as contribuições aqui arroladas, que o alicerce teórico consistente para fundamentar a teoria educacional e pedagógica na transição, para a superação do modo do capital organizar a produção dos bens materiais e imateriais é o marxismo - teoria formulada na luta histórica para a superação da fase préhistórica da humanidade, a fase das sociedades de classe.

Ao debate, aos estudos e pesquisas... à práxis...

\section{Bibliografia}

ALTHUSSER, Louis (s.d.). Ideologias e aparelhos ideológicos de Estado. Lisboa: Presença.

ANDREOTTI, Azilde (2007). Resenha do livro: LOMBARDI, José Claudinei e SAVIANI, Dermeval (orgs.) Marxismo e Educação debates contemporâneos. Campinas, SP: Autores Associados, 2005 In: Revista HISTEDBR On-line, Campinas, n.26, p.236-238, jun.

BALIBAR, Étienne (1995). A filosofia de Marx. Rio de Janeiro: Jorge Zahar.

BAUDELOT, Christian; ESTABLET, Roger (1971). L'école capitalista en France. Paris: Maspero.

CALDART, Roseli (2004). Pedagogia do Movimento dos Trabalhadores Rurais Sem Terra. 3ed. São Paulo: Expressão Popular.

COLETIVO DE AUTORES (1992). Metodologia do ensino de educação física. São Paulo: Cortez.

D`AGOSTINI, Adriana (2009). A educação do MST no contexto educacional brasileiro. Tese (Doutorado). UFBA. Programa de Pós-Graduação em Educação.

DANGEVILLE, Roger (Org.) (1976). Critique de l'éducation et de l'enseignement. Paris: Maspéro. 
DOMMANGET, Maurice (1972). Los grandes socialistas y la educación: de Platón a Lenin. Madrid: Fragua.

DUARTE, Newton (2001). Educação escolar, teoria do cotidiano e a escola de Vigotski. 3ed. Campinas: Autores Associados.

DUARTE, Newton (2003). Sociedade do conhecimento ou sociedade das ilusões? Quatro ensaios crítico-dialéticos em filosofia da educação. Campinas: Autores Associados.

DUARTE, Newton (2004a). Vigotski e o aprender a aprender: crítica às apropriações neoliberais e pós-modernas da teoria vigotskiana. 3ed. Campinas: Autores Associados.

DUARTE, Newton (Org.) (2004b). Crítica ao fetichismo da individualidade. Campinas: Autores Associados.

DUARTE, Newton (2004c). Vigotski e o "aprender a apreder": crítica às apropriações neoliberais e pós-modernas da teoria vigotskiana. Campinas: Autores Associados.

ENGELS, F. (1977). Do socialismo utópico ao socialismo científico. In: MARX, Karl; ENGELS, Friedrich. Textos 1. São Paulo: Edições Sociais. p.5-60.

FREITAS, Luiz Carlos (1995). Critica da organização do trabalho pedagógico e da didática. Campinas: Papirus.

FRIGOTTO, Gaudêncio. Os Circuitos Da História E O Balanço Da Educação No Brasil Na Primeira Década Do Século XXI. Conferência de Abertura da XXXIII Reunião Anual da Associação Nacional de Pesquisa e Pós-graduação em Educação (ANPED). Caxambu, MG, 17 de outubro de 2010.

GASPARIN, João Luiz (2002). Uma didática para a pedagogia histórico-crítica. Campinas: Autores Associados.

GERALDO, Antonio Carlos Hidalgo (2006). Didática de ciências e de biologia na perspectiva da pedagogia histórico-crítica. Bauru: UNESP, Tese de Doutorado.

GRAMSCI, Antonio (1968). Os intelectuais e a organização da cultura. Rio de Janeiro: Civilização Brasileira.

GRAMSCI, Antonio (1975). Quaderni del carcere. Torino: Einaudi.

GRAMSCI, Antonio (1978). Concepção dialética da história. 2ed. Rio de Janeiro: Civilização Brasileira.

http://abemarx.blogspot.com

http://www.faced.ufba.br/rascunho_digital/textos/853.htm

LAZARINI, Ademir Quintilio (2010). A relação entre capital e educação escolar na obra de Dermeval Saviani: apontamentos críticos. Tese (Doutorado) Universidade Federal de Santa Catarina. Orient. Paulo Sergio Tumolo. Programa de Pós-Graduação em Educação.

LOMBARDI, José Claudinei; SAVIANI, Dermeval (orgs.) (2005). Marxismo e educação: debates contemporâneos. Campinas: Autores Associados.

MANACORDA, Mario Alighiero (1964). Il marxismo e l'educazione. Roma: Armando.

MANACORDA, Mario Alighiero (1991). Marx e a pedagogia moderna. São Paulo: Cortez/Autores Associados.

MARCONDES DE MOARES, M. C. (org.) (2003). Iluminismo às avessas: produção de conhecimento e política de formação docente. Rio de Janeiro: DP\&A. 
MARSIGLIA, Ana Carolina Galvão (2005). Como transpor a pedagogia histórico-crítica para a prática pedagógica do professor na educação infantil? Bauru: UNESP. Trabalho de Conclusão do Curso de Pedagogia.

MARX, Karl (1973). Contribuição para a crítica da economia política. Lisboa: Estampa.

MARX, Karl (1974). Teses sobre Feuerbach. In: MARX, Karl; ENGELS, Friedrich. La ideología alemana. Montevideo/Barcelona: Pueblos Unidos/Grijalbo, p.665-668.

MARX, Karl (1978). Capítulo VI (inédito). O Capital [Livro I]. São Paulo: Ciências Humanas.

MARX, Karl; ENGELS, Friedrich (1998). Manifesto comunista. São Paulo: Boitempo.

MARX; ENGELS; LÊNIN; TROTSKY (2009). O programa da revolução. Brasília: Nova Palavra.

MELO, Adriana (2004). Mundialização da educação. Alagoas: EDUFAL.

MÉSZÁROS, István (2007). O desafio e o fardo do tempo histórico. São Paulo: Biotempo.

MST (2005). Dossiê Escola. Cadernos do MST.

NEVES, Lúcia Maria Wanderley (org.) (2005). A nova pedagogia da hegemonia: estratégias do capital para educar o consenso. São Paulo: Xamã.

ROSSI, Wagner Gonçalves (1981), Pedagogia do trabalho: raízes da educação socialista. São Paulo: Moraes.

SANTOS, César Sátiro (2005). Ensino de ciências: abordagem histórico-crítica. Campinas: Autores Associados.

SAVIANI, Dermeval (2005), Pedagogia histórico-crítica: primeiras aproximações. 9ed. rev. e ampl. Campinas: Autores Associados.

SAVIANI, Dermeval (2007a). Escola e democracia, 39ed. Campinas: Autores Asociados.

SAVIANI, Dermeval (2007b). Pedagogia: o espaço da educação na universidade. Cadernos de Pesquisa, v.37, n.130, jan./abr. 2007, p.99-134.

SAVIANI, Dermeval (2007c). Marxismo e pedagogia. Intervenção na Mesa IV: Teoria Marxista e Pedagogia Socialista. III Encontro Brasileiro de Educação e Marxismo. Salvador, 14 de novembro de 2007.

SCALCON. Suze Gomes (2002). À procura da unidade psicopedagógica: articulando a psicologia histórico-cultural com a pedagogia histórico-crítica. Campinas: Autores Associados.

SUCHODOLSKI, Bogdan (1966). Teoría marxista de la educación. México: Grijalbo.

SUCHODOLSKI, Bogdan (1976). Fundamentos de pedagogia socialista. Barcelona: Laia.

VENDARMINI. Célia (2009) A Educação na Perspectiva Materialista Histórica Dialética. UFSC. (mimeo).

VIANA, Marta L.D. (2011). A relação teoria e prática na Licenciatura em Pedagogia: um estudo critico do professor reflexivo-pesquisador. Dissertação (Mestrado) UFS, programa de Pós-Graduação em Educação. 
Notas:

\footnotetext{
${ }^{1}$ Professora Doutora Titular da FACED/UFBA. Pesquisadora 1D do CNPq.

2 Alusão ao Manifesto do Partido Comunista (1848), elaborado por Karl Marx (1818-1883) e Frederich Engels (1820-1895) (MARX; ENGELS, 1998).

${ }^{3}$ Os três intelectuais mencionados por Frigotto são: Florestan Fernandes, Francisco de Oliveira e Marilena Chauí.

${ }^{4}$ Intervenção na mesa redonda Teoria marxista e pedagogia socialista, integrante da programação do III EBEM, em 14 de novembro de 2007.
}

${ }^{5}$ A respeito desta tradição, consultar a página da Associação Brasileira de Educadores Marxistas (ABEM) $<$ http://abemarx.blogspot.com/>, organização demandada a partir das edições do EBEM, desde o ano de 2005.

6 Saviani mencionou em seu texto exposto no evento que "No que se refere à pedagogia histórico-crítica esse trabalho continua se desenvolvendo com o concurso de diversos colaboradores que vêm tentando explorar as potencialidades dessa concepção pedagógica em campos como o da didática (GASPARIN, 2002; GERALDO, 2006); psicopedagogia (SCALCON, 2002); ensino de ciências (SANTOS, 2005); e educação infantil (MARSIGLIA, 2005).

${ }^{7}$ Em um debate teórico com o professor Dr. Elenor Kunz formulei a concepção de emancipação humana a partir de Marx, pela mediação de Ivo Tonet, para contrapor-me à visão de emancipação humana dos fenomenólogos. Ver mais em <http://www.faced.ufba.br/rascunho_digital/textos/853.htm>.

Recebido em: $\quad$ 20/02/11

Aprovado em: 15/04/11 